\title{
Potential Operating Orbits for Fission Electric Propulsion Systems Driven by the SAFE-400
}

\author{
Mike Houts, Larry Kos, David Poston \\ NASA MSFC, TD40, Marshall Space Flight Center, Alabama, 35812 \\ (256)544-7143 / Fax: (256)544-5926 michael.houts@msfc.nasa.gov
}

\begin{abstract}
Safety must be ensured during all phases of space fission system design, development, fabrication, launch, operation, and shutdown. One potential space fission system application is fission electric propulsion (FEP), in which fission energy is converted into electricity and used to power high efficiency (Isp > 3000s) electric thrusters. For these types of systems it is important to determine which operational scenarios ensure safety while allowing maximum mission performance and flexibility. Space fission systems are essentially nonradioactive at launch, prior to extended operation at high power. Once high power operation begins, system radiological inventory steadily increases as fission products build up. For a given fission product isotope, the maximum radiological inventory is typically achieved once the system has operated for a length of time equivalent to several half-lives. After that time, the isotope decays at the same rate it is produced, and no further inventory builds in. For an FEP mission beginning in Earth orbit, altitude and orbital lifetime increase as the propulsion system operates. Two simultaneous effects of fission propulsion system operation are thus (1) increasing fission product inventory and (2) increasing orbital lifetime. Phrased differently, as fission products build up, more time is required for the fission products to naturally convert back into non-radioactive isotopes. Simultaneously, as fission products build up, orbital lifetime increases, providing more time for the fission products to naturally convert back into non-radioactive isotopes. Operational constraints required to ensure safety can thus be quantified.
\end{abstract}

\section{INTRODUCTION}

The fission process was first reported in 1939, and in 1942 the world's first man-made self-sustaining fission reaction was achieved. Creating a self-sustaining fission chain reaction is conceptually quite simple. All that is required is for the right materials to be placed in the right geometry - no extreme temperatures or pressures required - and the system will operate. Since 1942 fission systems have been used extensively by governments, industry and universities. Fission systems operate independently of solar proximity or orientation, and are thus well suited for deep space or planetary surface missions. In addition, the fuel for fission systems (highly enriched uranium) is essentially non-radioactive, containing 0.064 curies $/ \mathrm{kg}$. This compares quite favorably to current nuclear systems ( $\mathrm{Pu}-238$ in radioisotope systems contains 17,000 curies $/ \mathrm{kg}$ ) and certain highly futuristic propulsion systems (tritium in D-T fusion systems would contain 10,000,000 curies $/ \mathrm{kg}$ ). An additional comparison is that at launch a typical space fission propulsion system would contain an order of magnitude less onboard radioactivity than did Mars Pathfinder's Sojourner Rover, which used radioisotopes for thermal control. The primary safety issue with fission systems is avoiding inadvertent system start - addressing this issue through proper system design is straightforward. The energy density of fission is seven orders of magnitude greater than that of the best chemical fuels, and if properly utilized is more than adequate for enabling rapid, affordable access to any point in the solar system.

One potential space fission system application is fission electric propulsion (FEP), in which fission energy is converted into electricity and used to power high efficiency (Isp > 3000s) electric thrusters. For these types of systems it will be important to determine which operational scenarios ensure safety while allowing maximum mission performance and flexibility. Space fission systems are essentially non-radioactive at launch, prior to extended operation at high power. Once high power operation begins, system radiological inventory steadily increases as fission products build up. For a given fission product isotope, the maximum radiological inventory is 
typically achieved once the system has operated for a length of time equivalent to several half-lives. After that time, the isotope decays at the same rate it is produced, and no further inventory builds in. For an FEP mission beginning in Earth orbit, altitude and orbital lifetime increase as the propulsion system operates. Two simultaneous effects of fission propulsion system operation are thus increasing fission product inventory and increasing orbital lifetime. Phrased differently, as fission products build up, more time is required for the fission products to naturally convert back into non-radioactive isotopes. Simultaneously, as fission products build up, orbital lifetime increases, providing more time for the fission products to naturally convert back into non-radioactive isotopes. Operational constraints required to ensure safety can thus be quantified.

\section{THE 400 KILOWATT THERMAL SAFE AFFORDABLE FISSION ENGINE (SAFE-400)}

NASA's baseline Phase 1 space fission electric propulsion system is based on the $400 \mathrm{kWt}$ Safe Affordable Fission Engine (SAFE-400) reactor. Hardware-based research and development related to Phase 1 space fission system development has been ongoing since 1996 (Houts, 1997). In addition to early module tests, a $30 \mathrm{kWt} \mathrm{SAFE} \mathrm{core}$ has been fabricated and tested, and a $100 \mathrm{kWt}$ core is currently in fabrication. The next step after fabrication and testing of the $100 \mathrm{kWt}$ core is fabrication and testing of a $400 \mathrm{kWt}$ core that is nearly flight-prototypic. Design details are being added to the $400 \mathrm{kWt}$ core, and fabrication should begin in 2003 . While SAFE performance must be adequate to enable missions of interest, the emphasis of Phase 1 system design and development is on safety, affordability, and schedule. Key features of Phase 1 systems include a high level of testability, utilization of established technology, and utilization of existing / operational facilities. Details of recent efforts at NASA MSFC related to the SAFE are given in Van Dyke, 2002. Details of the reference Phase $1400 \mathrm{kWt}$ design (SAFE-400) are given in Poston, 2002. A comparison of Phase 1 system options is given in Houts, 2002. A picture of a coupled SAFE-30 / Stirling engine test is shown in Figure 1.

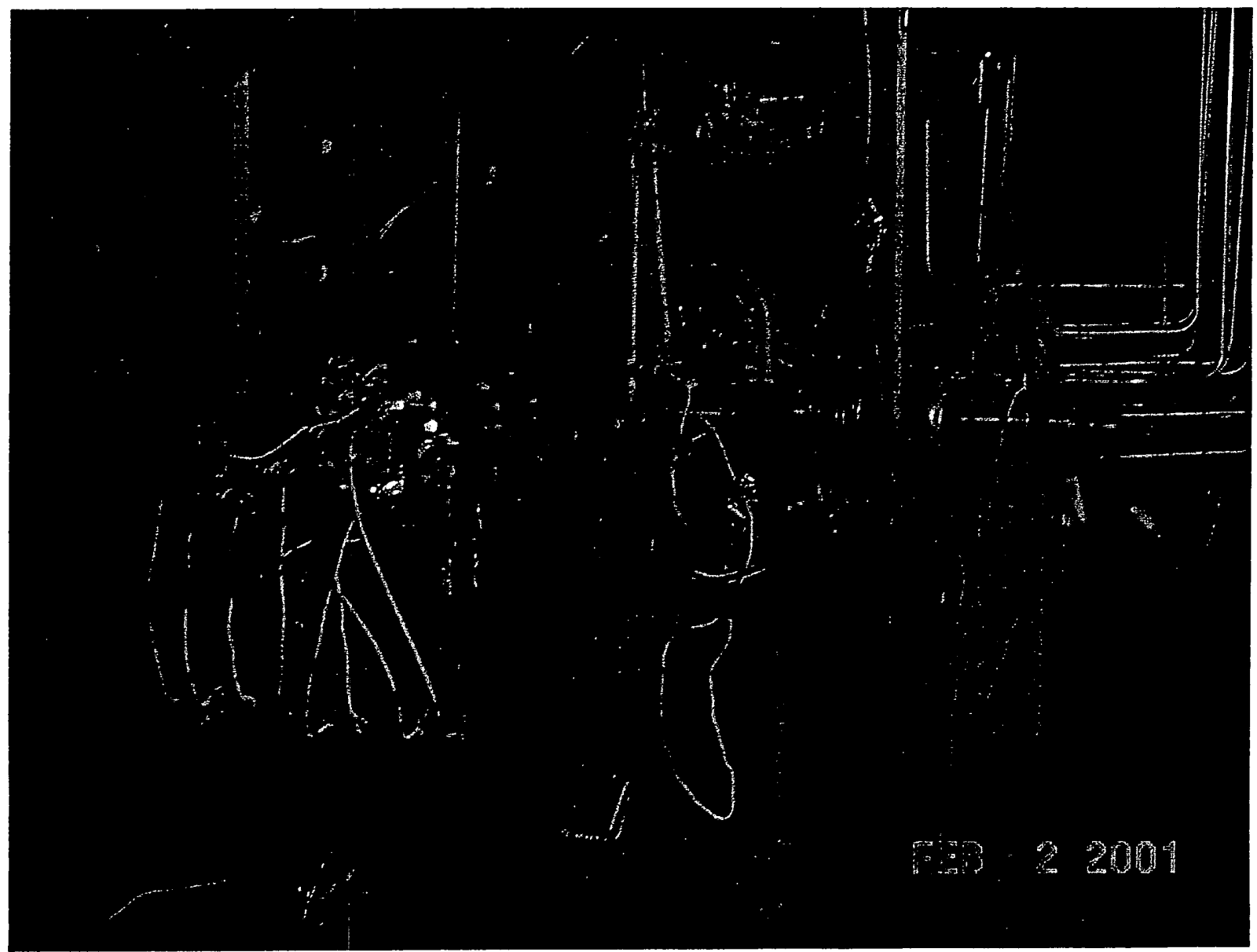

FIGURE 1. SAFE-30 Providing Thermal Power to a Stirling Engine, Resulting in Electricity Production. 


\section{ORBITAL LIFETIME AS A FUNCTION OF ALTITUDE}

Orbital lifetime as a function of altitude was calculated for three spacecraft mass-to-frontal area ratios: $82 \mathrm{~kg} / \mathrm{m}^{2}$, $250 \mathrm{~kg} / \mathrm{m}^{2}$, and $1000 \mathrm{~kg} / \mathrm{m}^{2}$. Spacecraft altitudes of 550 to $700 \mathrm{~km}$ were examined. The range was chosen based on Space Shuttle capabilities and atmospheric drag. The payload capability (including attachment hardware) of the space shuttle to a $550 \mathrm{~km}$ orbit exceeds $13,500 \mathrm{~kg}$. This payload capability is significantly greater than that required by all but the most ambitious Phase 1 FEP missions. At $700 \mathrm{~km}$ atmospheric drag is extremely low (effectively zero above $800 \mathrm{~km}$ ); however, the space shuttle is not capable of reaching that orbit. The code "LIFTIM" (Alford, 1974)

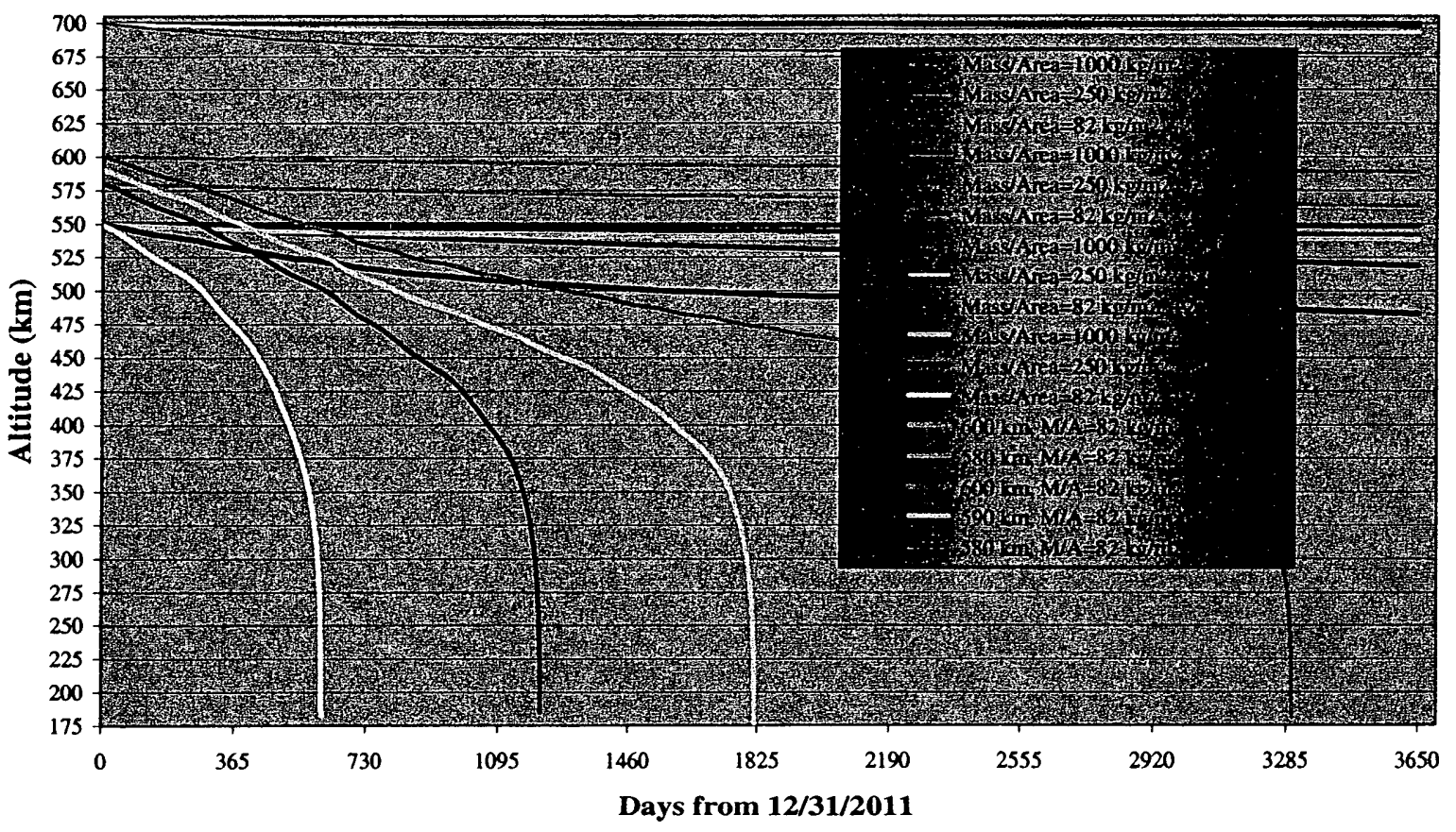

FIGURE 2. Orbital Lifetime as a Function of Altitude for Three Spacecraft Mass-to-Area Ratios.

was used to perform the calculations. An initial orbit insertion date of 31 December 2011 was assumed, and predicted fluctuations of the Earth's atmosphere were taken into account. Results of the calculations are shown in Figure 2. The calculations are conservative in that the launch date is chosen to be just prior to peak atmospheric density at altitude. Atmospheric density values two standard deviations above the predicted value $(+2 s)$ and two standard deviations below the predicted value $(-2 \mathrm{~s})$ are plotted.

As shown in Figure 2, an $82 \mathrm{~kg} / \mathrm{m}^{2}$ spacecraft (e.g. an $8200 \mathrm{~kg}$ FEP vehicle with $100 \mathrm{~m}^{2}$ of frontal area) placed in a $550 \mathrm{~km}$ orbit is estimated to require 20 months to re-enter, assuming a 12/31/2011 launch and a $+2 \mathrm{~s}$ (worst-case) atmosphere. The same spacecraft placed in a $600 \mathrm{~km}$ orbit would require over nine years to re-enter, given the same assumptions. Figure 2 also shows that at $250 \mathrm{~kg} / \mathrm{m}^{2}$ (e.g. $10,000 \mathrm{~kg}, 40 \mathrm{~m}^{2}$ area) orbital lifetime for missions starting at $550 \mathrm{~km}$ exceeds ten years. Orbits of $700 \mathrm{~km}$ or higher all have lifetimes much greater than 10 years (for the 82 , 250 , and $1000 \mathrm{~kg} / \mathrm{m}^{2}$ spacecraft analyzed).

Given a reasonable system specific power and specific impulse, increasing the orbital altitude of an FEP system from 550 to $600 \mathrm{~km}$ will require about one day of full-power operating time. If the expelled propellant mass is 
considered negligible, then for the $82 \mathrm{~kg} / \mathrm{m}^{2}$ case one day of operation effectively increases the orbital lifetime by over seven years. For spacecraft configurations that result in greater than $82 \mathrm{~kg} / \mathrm{m}^{2}$, the orbital lifetime would be increased even more.

\section{RADIOLOGICAL INVENTORY AS A FUNCTION OF LIFETIME}

Radiological inventory of the SAFE-400 at launch is on the order of 10 Curies (primarily due to U-234). Radiological inventory as a function of time after shutdown was calculated for the SAFE-400 and for spacecraft previously launched by NASA using the code "MONTEBURNS" (Poston, 1999). Radiological inventory as a function of time after shutdown for various SAFE- 400 operating times and for various spacecraft currently in Earth orbit is shown in Figure 3. As shown in Figure 3, SAFE-400 radiological inventory decreases rapidly after shutdown, and more rapidly than the inventory in Pu-238 powered spacecraft. Seven days of full power FEP operating time is typically sufficient to raise the orbital altitude of a spacecraft by several hundred kilometers, placing the spacecraft above the point where atmospheric drag is significant for most reasonable starting orbits. As shown in Figure 3, following one week of full-power operation SAFE-400 radiological inventory drops below 100 Curies within 3 years. For full-power operation of 1 day, radiological inventory drops below 100 Curies in about a year. The actual potential radiological hazard from a reentry would depend not only on radiological inventory, but also on radiation type and system geometry following reentry.

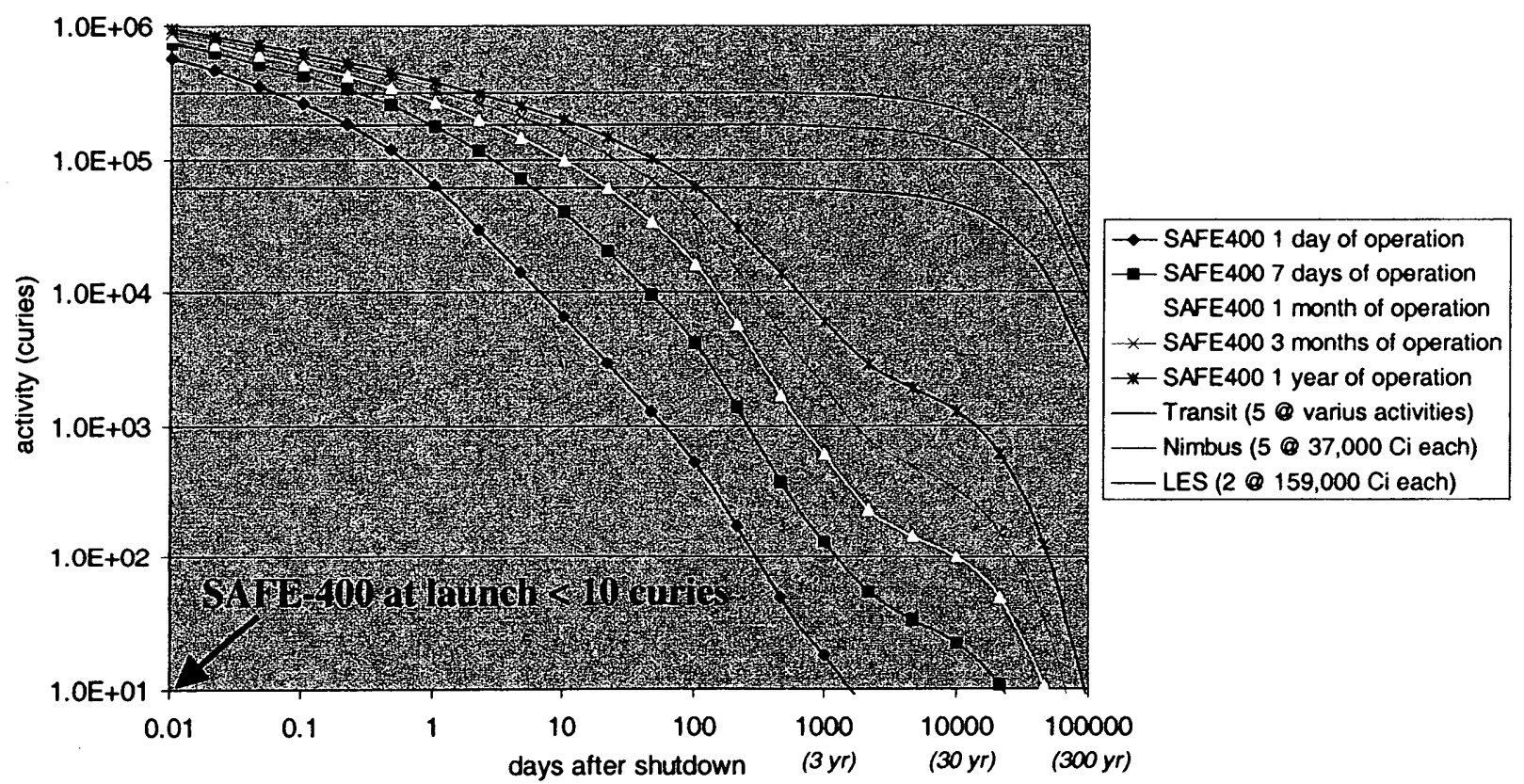

FIGURE 3. Radiological Activity of Currently Orbiting Spacecraft and the SAFE-400 as a Function of Time.

\section{OBSERVATIONS}

All potential civilian FEP missions currently under discussion would not return to low Earth orbit following extended operation. For these missions, preliminary calculations indicate that strict mission safety requirements are met if FEP operation begins above an orbital altitude of about $500 \mathrm{~km}$. For these scenarios, system radiological inventory during a worst-case failure / re-entry is comparable to that at system launch. If more detailed calculations sustain this observation, then deploying FEP systems directly out of the space shuttle cargo bay (no additional stages required) may be a viable option. Deployment directly from the space shuttle has several potential advantages, including the extremely high reliability of the space shuttle (>99.8\%), the large volume of the shuttle cargo bay, the 
shuttle's delivered payload mass capability, the presence of astronauts to help ensure proper FEP system deployment and start, and the ability to return the FEP system to earth if desired. If a decision is made against using the space shuttle to deploy the FEP vehicle, it will still be important to determine the desired range of initial operating orbits to ensure mission safety while optimizing mission performance and flexibility.

\section{RECOMMENDATIONS FOR FUTURE RESEARCH}

Mission options for potential NASA Phase 1 FEP systems should continue to be explored. More detailed mission design and analysis should be performed to define missions that ensure safety while providing maximum mission performance and flexibility. The benefits and issues associated with using the space shuttle to deploy FEP systems should be further investigated. Increased FEP system definition will add fidelity to mission analyses.

\section{ACKNOWLEDGMENTS}

Unless otherwise referenced, the research reported in this paper was funded by and performed at NASA's Marshall Space Flight Center or at Los Alamos National Laboratory.

\section{REFERENCES}

Alford. R.L. and Liu, J.J. (1974) The Orbital Decay and Lifetime (LIFTIM) Prediction Program, M-240-1278, Northrop Services, Inc., Huntsville, AL.

Houts, M.G., Poston, D.I.. Emrich, W.J. (1997) "Heatpipe Power System and Heatpipe Bimodal System Design and Development Options," in Space Nuclear Power and Propulsion. edited by Mohamed S. El-Genk and Mark D. Hoover, DOE Conf 970115. American institute of Physics, New York, pp. 1317-1322.

Houts, M.G. et al. (2002) "Phase 1 Space Fission Propulsion System Design Considerations," to be published in Space Nuclear Power and Propulsion, edited by Mohamed S. El-Genk, American Institute of Physics, New York, 2002, within these proceedings.

Poston, D.I. and Trellue, H.R., "User's Manual, Version 2.0 for MONTEBURNS. Version 5B," LA-UR-99-4999, September 1999, Los Alamos National Laboratory.

Poston, D. I. et al. (2002) "Design and Analysis of the SAFE-400 Reactor," to be published in Space Nuclear Power and Propulsion. edited by Mohamed S. El-Genk. American Institute of Physics, New York, 2002, within these proceedings.

Vandyke, M.K. et al. (2002) "Safe Affordable Fission Engine (SAFE) Testing and Development Progress," to be published in Space Nuclear Power and Propulsion, edited by Mohamed S. El-Genk, American Institute of Physics, New York, 2002. within these proceedings. 